\title{
Iron Supplementation Alters Heme and Heme Oxygenase 1 (HO-1) Levels In Pregnant Women in Ghana
}

\author{
Hassana Salifu' ${ }^{*}$, Nana 0. Wilson ${ }^{1}$, Mingli Liu ${ }^{1}$, Carmen Dickinson-Copeland ${ }^{1}$, Nelly Yatich ${ }^{2}$, \\ John Keenan ${ }^{2}$, Cornelius Turpin ${ }^{2}$, Pauline Jolly², Richard Gyasi ${ }^{3}$, Andrew A. Adjei ${ }^{3}$ and \\ Jonathan K. Stiles ${ }^{1 *}$ \\ ${ }^{1}$ Department of Microbiology, Biochemistry and Immunology, Morehouse School of Medicine \\ ${ }^{2}$ University of Alabama, Birmingham Alabama, Department of Epidemiology \\ ${ }^{3}$ University of Ghana Medical School, Department of Pathology, Korle-Bu Teaching Hospital, Accra, Ghana
}

Received: August 11, 2016; Accepted: September 9, 2016; Published: September 14, 2016

*Corresponding author: Hassana Salifu and Jonathan K. Stiles, Department of Microbiology, Biochemistry and Immunology, Morehouse School of Medicine,E-mail: hSalifu@msm.edu, jstiles@msm.edu

\begin{abstract}
Background: Iron supplementation is recommended for pregnant women to meet their iron requirement for a healthy pregnancy. The benefits and risks of universal iron supplementation during pregnancy in malaria endemic countries are currently being debated. As part of a broader study that focused on the effect of heme/ HO- 1 on pregnancy outcomes in malaria in pregnancy, we determined the association between iron supplementation and free heme levels in blood of pregnant women with and without malaria in Ghana. We hypothesized that pregnant women with malaria who took iron supplements will have higher levels of Heme/ HO-1 than those who did not take iron supplements.
\end{abstract}

Methods: A total of 337 women were recruited for this study. Blood samples were collected for malaria diagnosis and heme/ HO-1 measurement. Quantification of heme was done using a heme colorimetric assay kit and HO-1 levels were performed using EnzymeLinked Immunosorbent Assay (ELISA) on plasma samples.

Results: Malaria positive iron supplemented women, in their third trimester, had significantly higher median levels of heme $59.3(43.1$ - 60.4) than non-malaria iron supplemented women $35.7(33.0-62.2), p=0.026$. Also, malaria positive iron supplemented women had significant higher median levels of HO-16.2(IQR 4.9 - 8.1) than pregnant women who did not take iron supplements 2.9 (IQR $2.1-3.8), p=<0.001$

Conclusion: Although iron supplementation may be highly beneficial and improve pregnancy outcomes for iron deficient or anemic mothers, it is also likely that iron supplementation for pregnant women who are not iron deficient may put this group of women at risk for adverse pregnancy outcomes. Findings from this study sheds light on the effect of iron supplementation on malaria derived heme in pregnancy, which may inform how iron supplementation is recommended for pregnant women who are not iron deficient.

Keywords: Heme; Heme oxygenase-1; Iron supplementation; Placental malaria; Preterm delivery

\section{Abbreviations}

ROS: Reactive Oxygen Species; HO-1: Heme Oxygenase-1; CO: Carbon Monoxide; ELISA: Enzyme-Linked Immunosorbent Assay; LBW: Low Birth Weight; PTD: Pre-Term Delivery; Hb: Hemoglobin; RBCs: Red Blood Cells; HRPII-RDT: HistidineRich Protein II - Rapid Diagnostic Test; PCR: Polymerase Chain Reaction; KATH: Komfo Anokye Teaching Hospital; ANC: Antenatal Care; DNA: Deoxyribonucleic Acid; AGA: Appropriate For Gestational Age; SGA: Small For Gestational Age; LGA: Large For Gestational Age; WBC: White Blood Cell; SCD: Sickle Cell Disease; Hx: Hemopexin

\section{Background}

Plasmodium falciparum malaria is a serious public health concern in most sub-Saharan African countries and it threatens over 200 million people worldwide resulting in 438,000 deaths annually with pregnant women and children at high risk [1]. In pregnant women, malaria infection is associated with high risks of severe disease with maternal anemia being one of the major complications [2]. Malaria-induced anemia is dependent on several factors including hemolysis or direct destruction of parasitized red blood cells that occur both intravascularly and by sequestration in the microcirculation mainly in the spleen, hypersplenism accompanied by a reduction in all three blood cell types (erythrocytes, thrombocytes and leucocytes) and shortened red cell survival through nonspecific and specific immune responses [3,4] In addition, malaria infection amongst pregnant women is most often asymptomatic and often goes undetected, but is associated with placental parasitization. Placental malaria infection is associated with Low Birth Weight (LBW), Pre-Term Delivery (PTD), intrauterine growth retardation and neonatal mortality [5-8].

Pregnant women are routinely recommended to take iron supplements during pregnancy with the aim of meeting the 
increased iron demands during pregnancy [9]. Different studies have shown that iron supplementation results in positive maternal and neonatal outcomes [10]. However, the recent guidelines on antenatal care by the National Institute of Clinical Excellence in the UK does not recommend universal iron supplementation for all pregnant women because reports on the benefits of iron supplementation on maternal and infant health were inconsistent and showed negative side effects like gastroenteritis, reduced absorption of non-heme iron and increased oxidative stress [11]. Their recommendation is that iron supplementation should only be limited to women with Hemoglobin $(\mathrm{Hb})$ concentrations $<11 \mathrm{~g} / \mathrm{dL}$ in their first trimester or $<10.5 \mathrm{~g} / \mathrm{dL}$ at 28 weeks of gestation [12].

Although it's needed to meet the demands in pregnancy, iron supplementation paradoxically predisposes pregnant women and children to malaria and adverse outcomes [1315]. Iron is essential for growth, proliferation and survival of malaria parasites [16]. The parasite multiplies 8-32 times in the presence of iron during a single intra-erythrocytic lifecycle [17]. Clark, et al. [15] demonstrated that host iron status and iron supplementation mediate susceptibility to erythrocytic stages of P. falciparum through elevated erythropoietic rate. The mechanisms by which iron supplementation causes adverse pregnancy outcomes still remain unclear. In addition, parasite biomass causes hemolysis of Red Blood Cells (RBCs) resulting in production of parasite derived factors and host factors such as heme and Heme Oxgenase-1 (HO-1). Recently we reported that free heme and heme mediated signaling pathways are central in the pathogenesis of severe malaria [18]. We have previously shown in an in vitro model that excess free heme, a product of hemolysis associated with erythrocyte damage due to malaria infection, compromises the blood brain barrier, causing the barrier to become leaky and dysfunctional thereby exacerbating cerebral malaria complications [19]. Other studies have implicated HO-1 in the pathogenesis of, severe malaria severe preeclampsia, a pregnancy complication [20-23]. Animal studies demonstrate that the heme oxygenase system is an important regulator of placental development [24]. To our knowledge, the effect of iron supplementation on free heme in blood of pregnant women in malaria endemic region has not been studied. The objective of this study is to determine the effect of iron supplementation on free plasma heme in pregnant women with or without malaria infections. We hypothesized that pregnant women with malaria who took iron supplements will have higher levels of Heme and HO-1 than those who did not take iron supplements.

\section{Materials}

Whole blood ( $8 \mathrm{~mL}$ ) was collected by venipuncture from the pregnant women at the time of delivery. The blood samples were used for heme and HO-1 analysis using a heme colorimetric assay kit from Bioassay systems and Human HO-1 Elisa kit from Enzo Life Sciences respectively. Whole blood was also used to detect plasmodium falciparum histidine-rich protein II via malaria antigen test (Histidine-Rich Protein II - Rapid Diagnostic Test [HRPII-RDT]). Dried blood spot was collected for malaria diagnosis by Polymerase Chain Reaction (PCR).

\section{Methods \\ Ethical Considerations}

IRB approval was sought and approved by Morehouse School of Medicine and the Committee on Human Research, Publications and Ethics, School of Medical Sciences, Kwame Nkrumah University of Science and Technology Kumasi and Korle $\mathrm{Bu}$ Teaching Hospital Accra for this study. Each participant of the study signed an informed consent form and for minors/children in the study, parent/guardian signed a written informed consent form on behalf of the minors/children enrolled in the study.

\section{Study design and population}

This was a cross-sectional study conducted during November-December 2006, of women who had a singleton and uncomplicated pregnancy with no clinical symptoms of malaria (asymptomatic malaria) presenting at their third trimester for delivery at two hospitals in Kumasi, the Komfo Anokye Teaching Hospital (KATH) and the Manhyia Polyclinic, and the Korle$\mathrm{Bu}$ teaching hospital in Accra. Women were screened when they came for their antenatal care. These women did not show any clinical symptoms of malaria when they were screened. They were asymptomatic but positive for malaria at delivery. This cross-sectional study does not provide information on the duration of exposure to parasites.

\section{Enrollment Criteria}

All women who had a singleton, uncomplicated pregnancy wereinvited to participate. Women were identified fromadmission records. Women with Multiple births, previous caesarian section, hemorrhage, pre-eclampsia; sickle cell and hypertension were excluded from the study. After informed consent was obtained, a questionnaire was administered by a trained interviewer. The questionnaire included information on demographic characteristics (age, education, socioeconomic status, residence, and toilet facilities), obstetric history for current and previous pregnancies (stillbirth, ectopic pregnancy, preterm delivery, and LBW), illnesses, and treatments during the pregnancy (iron supplements, Malaria prophylaxis etc). Questionnaire content was derived from a model questionnaire recommended for use by Roll Back Malaria Monitoring and Evaluation Reference group (malaria indicator survey, women's questionnaire). Obstetric information was obtained from the women's Antenatal Care (ANC) charts. ANC charts provided information on gestational age at first ANC visit, number of antenatal care visits, gestational age as assessed by palpation or ultrasound at first ANC visit, tetanus immunization, malaria prophylaxis etc. Whole blood(8 $\mathrm{mL}$ ) was collected by venipuncture from the pregnant women before delivery for determination of hemoglobin levels, serum folate levels and malaria antigen test (Histidine-Rich Protein II - Rapid Diagnostic Test [HRPII-RDT])[25,26]. Birth outcome information was collected after delivery. The blood sample was used for heme/HO-1 analysis and for Deoxyribonucleic Acid (DNA) extraction. A dried blood spot was collected for malaria diagnosis. Plasmodium DNA was extracted from the dried blood on the filter paper. HRPII-RDT was used to initially detect 
plasmodium falciparum histidine-rich protein II and Polymerase Chain Reaction (PCR) was used to confirm the presence of plasmodium falciparum DNA and to exclude plasmodium vivax, plasmodium malariae, and plasmodium ovale [27]. All pregnant women with positive HRPII and PCR for P. falciparum were classified as malaria positive and those with negative HRPII and PCR were classified as malaria negative.

\section{Heme and H0-1 quantification}

To quantify heme, Plasma was centrifuged for $30 \mathrm{~min}$ at room temperature at $1200 \mathrm{xg}$ to remove contaminating red blood cells. Total heme was quantified using a Heme Colorimetric Assay Kit according to the manufacturer's instructions (BioAssay System, Hayward, CA). HO-1 levels in the plasma of pregnant women with and without malaria were measured by ELISA using a Human HO-1 Enzyme Immunoassay kit (ENZO Life Sciences, Plymouth Meeting, PA). HO-1 levels were measured using optimal concentrations of standards and antibodies according to the manufacturer's instructions. The data was analyzed at 450 nm wavelength using a Spectra Max 190 fluorescence micro plate reader (Molecular Devices Corp., Sunnyvale, CA).

\section{Definition of Variables}

Uncomplicated pregnancy: absence of hypertension, preeclampsia, no history of a previous caesarean section and hemorrhage, and a normal presentation of the fetus. Malaria infection: presence of malaria antigen in the mother's peripheral blood at the time of delivery. Anemia: hemoglobin levels $<11 \mathrm{~g} /$ $\mathrm{dL}$ of blood. Severe anemia: hemoglobin level $<8 \mathrm{~g} / \mathrm{dL}$. Low Birth Weight (LBW): weight less than $2500 \mathrm{~g}$ at birth regardless of gestational age. Term baby: birth between 37 and 42 weeks Preterm Delivery (PTD): delivery occurring before 37 completed weeks of gestation [25,28]. Post-term: birth after 42 weeks of gestation.

\section{Statistical Analysis}

Data analysis was conducted using SPSS software version 18.0 for windows (SPSS Inc., Chicago, IL). Socio-demographic differences and obstetric characteristics were compared using Pearson Chi-square or one-way analysis of variance where appropriate to determine statistical differences between the groups. Mann Whitney test was used to compare for statistical differences in heme levels and HO-1 levels among pregnant women. Chi square was used to determine the factors associated with pre-term delivery. All analyses with a $P$ value of $\leq 0.05$ were considered significant.

\section{Results}

\section{Study population}

A total of 337 women were recruited for this study. The age distribution for the women ranged from 15-45 years of age with the median age of the women being 26 years; $13.4 \%$ were less than 20 years, and $23.6 \%$ had a weekly income of less than US\$10. A total of $90(26.7 \%)$ pregnant women had malaria and a total of 247 (73.3\%) did not have malaria. Out of 337 women, $61(18 \%)$ women had preterm delivery and 62 (18.4\%) women had low birth weight deliveries. About $73 \%$ of the women who used Sulfadoxine Pyrimethamine (SP) as a form of intermittent preventive treatment in pregnancy (IPTp) were malaria negative.

\section{Hematological Characteristics}

There were significant differences in hematological characteristics between non-malaria and malaria subjects. Nonmalaria subject had significant higher levels of hemoglobin (non-malaria, $12.6 \mathrm{gm} / \mathrm{dL}$ vs. malaria, $11.6 \mathrm{gm} / \mathrm{dL}, p<0.0001$ ), White Blood Cell (WBC) (non-malaria, 7.1×103/ mL vs. malaria, $6.0 \times 103 / \mathrm{mL}, p<0.0001$ ) and platelet (non-malaria, 243×103/ $\mathrm{mL}$ vs. malaria, $171 \times 103 / \mathrm{mL}, p<0.0001$ ) (Table 1 ).

\section{Factors associated with Preterm Deliveries among Women with and without Malaria}

Table 2 shows the demographic and obstetric characteristics of women by delivery status. The results show that parity ( $p=$ $0.036)$, weekly Income $(p<0.0001)$ and marital status $(p=0.011)$ were associated with PTD (Table 2). Single women, poorer women, and Nulliparous women, had an increased susceptibility to PTD (Table 2). Age, formal education, and doses of Sulfadoxine Pyrimethamine (sp) were not factors associated with preterm delivery.

\section{P. falciparum infection in pregnancy is associated with increased free plasma heme}

To examine the association between Heme and malaria infection, we measured the heme levels in malaria and nonmalaria pregnant women. Women with malaria had significantly higher median levels of heme in their peripheral blood $(42.3 \mu \mathrm{M})$ than non-malaria pregnant women $(34.6 \mu \mathrm{M}), p=0.006$ (figure 1).

\section{P. falciparum infection in pregnancy is associated with increased plasma $\mathrm{HO}$-1}

To examine the association between $\mathrm{HO}-1$ and malaria infection, we measured the HO-1 levels in malaria and nonmalaria pregnant women. Women with malaria had significantly higher median circulating HO-1 levels $(7.3 \mathrm{ng} / \mathrm{ml})$ than nonmalaria women $(5.6 \mathrm{ng} / \mathrm{ml}), p<0.0001$ (figure 2).

\begin{tabular}{|c|c|c|c|}
\hline Characteristics & $\begin{array}{l}\text { Non-malaria } \\
(I Q R) N=(247)\end{array}$ & $\begin{array}{l}\text { Malaria (IQR) N } \\
=(90)\end{array}$ & $p$-value \\
\hline $\begin{array}{l}\text { Hemoglobin } \\
(\mathrm{gm} / \mathrm{dL})\end{array}$ & $12.6(11.6-14.5)$ & $11.6(10.9-13.6)$ & $<0.0001$ \\
\hline $\mathrm{WBC}\left(\mathrm{x} 10^{3} / \mathrm{mL}\right)$ & $7.1(5.6-7.7)$ & $6.0(4.3-7.6)$ & $<0.0001$ \\
\hline $\begin{array}{l}\text { Platelet }\left(\mathrm{x} 10^{3} /\right. \\
\mathrm{mL})\end{array}$ & $243(164-311)$ & 171 (85 - 209) & $<0.0001$ \\
\hline \multicolumn{4}{|c|}{$\begin{array}{l}\text { Pearson Chi-square }\left(\mathrm{X}^{2}\right) \text { test was used to compare for statistical } \\
\text { differences among pregnant women. Statistical significance was set at } \\
P<0.05 \text {. }\end{array}$} \\
\hline
\end{tabular}




\section{Iron supplementation in pregnancy is associated with increased free plasma heme}

Women who took iron supplements had significantly higher median levels of heme $(59.3 \mu \mathrm{M})$ than those who did not take iron supplements $(35.7 \mu \mathrm{M}), p=0.026$ (figure 3 ).

\section{Iron supplementation in pregnancy is associated with increased plasma $\mathrm{HO}-1$}

Women who took iron supplements had significantly higher median levels of H0-1 (3.9 ng/ ml) than those who did not take iron supplements $(2.8 \mathrm{ng} / \mathrm{ml}), p=<0.001$ (figure 4 ).

\section{Iron supplementation in pregnancy is associated with increased free plasma heme in women with malaria}

Table 2: Demographic and obstetric characteristics of women by delivery status, $(\mathrm{N}=337)$.

\begin{tabular}{|l|l|l|l|}
\hline Characteristics & $\begin{array}{l}\text { Full } \\
\text { Delivery }\end{array}$ & $\begin{array}{l}\text { Term P r e t e r m } \\
\text { delivery }\end{array}$ & P-values \\
\hline Age & \multicolumn{3}{|l|}{} \\
\hline$<20$ & $29(10.6 \%)$ & $12(19.7 \%)$ & 0.205 \\
\hline $20-24$ & $78(28.6 \%)$ & $19(31.1 \%)$ & \\
\hline $25-29$ & $83(30.4 \%)$ & $15(24.6 \%)$ & \\
\hline$\geq 30$ & $83(30.4 \%)$ & $15(24.6 \%)$ & \\
\hline
\end{tabular}

\section{Formal Education}

\begin{tabular}{|c|c|c|c|}
\hline None & $57(20.9 \%)$ & $13(21.3 \%)$ & 0.554 \\
\hline Primary & $40(14.7 \%)$ & $13(21.3 \%)$ & \\
\hline Middle School & $32(11.7 \%)$ & $9(14.8 \%)$ & \\
\hline Junior Secondary & $97(35.5 \%)$ & $22(36.1)$ & \\
\hline$\geq$ Senior Secondary & $42(15.4 \%)$ & $4(6.6 \%)$ & \\
\hline \multicolumn{4}{|l|}{ Marital Status } \\
\hline Single & 51(18.7\%) & $30(49.2 \%)$ & 0.011 \\
\hline Married & $161(59.0 \%)$ & $23(37.7 \%)$ & \\
\hline Living in Union & $61(22.3 \%)$ & $8(13.1 \%)$ & \\
\hline
\end{tabular}

\section{Weekly Income in dollars}

\begin{tabular}{|l|l|l|l|}
\hline$<10$ & $30(11.0 \%)$ & $26(42.6 \%)$ & $<0.0001$ \\
\hline $10-20$ & $14(5.1 \%)$ & $7(11.5 \%)$ & \\
\hline $20-40$ & $135(49.5 \%)$ & $15(24.6 \%)$ & \\
\hline$\geq 40$ & $92(33.7 \%)$ & $13(21.3 \%)$ & \\
\hline
\end{tabular}

\section{Parity}

\begin{tabular}{|l|l|l|l|}
\hline Nulliparous & $98(35.9 \%)$ & $31(50.8 \%)$ & 0.036 \\
\hline Primiparous & $122(44.7 \%)$ & $25(41.0 \%)$ & \\
\hline Multiparous & $53(19.4 \%)$ & $5(8.2 \%)$ & \\
\hline Sulfadoxine pyrimethamine doses & & \\
\hline One & $65(29.5 \%)$ & $11(45.8 \%)$ & 0.252 \\
\hline Two & $113(51.4 \%)$ & $10(41.7 \%)$ & \\
\hline Three & $42(19.1 \%)$ & $3(12.5 \%)$ & \\
\hline
\end{tabular}

Pearson Chi-square $\left(\mathrm{X}^{2}\right)$ test was used to compare for statistical differences among pregnant women. Statistical significance was set at $P<0.05$.

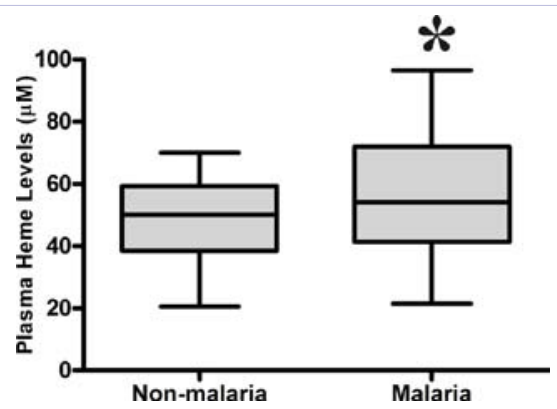

Figure 1: Free plasma heme levels among malaria and non-malaria women. Mann Whitney test was used to compare for statistical differences in heme levels among pregnant women. Statistical significance was set at $P<0.05$.

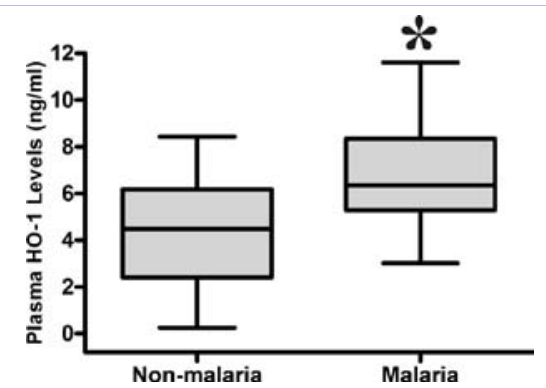

Figure 2: Plasma HO-1 levels among malaria and non-malaria women Mann Whitney test was used to compare for statistical differences in HO-1 levels among pregnant women. Statistical significance was set at $P<0.05$.

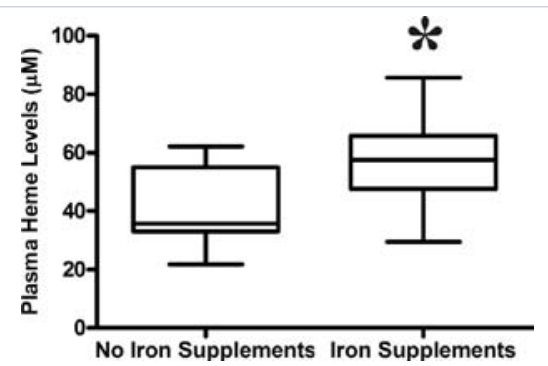

Figure 3: Free plasma heme levels among women with or without iron supplementation. Mann Whitney test was used to compare for statistical differences in heme levels among pregnant women who took iron supplements. Statistical significance was set at $P<0.05$.

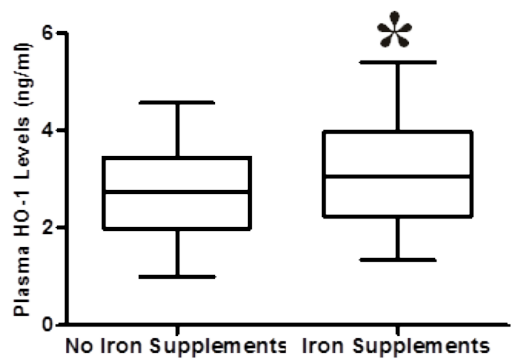

Figure 4: Plasma HO-1 levels among women with or without iron supplementation. Mann Whitney test was used to compare for statistical differences in HO-1 levels among pregnant women who took iron supplements. Statistical significance was set at $P<0.05$. 
In the current study, iron supplementation was associated with increased free plasma heme in women with malaria. Malaria positive women who took iron supplements had significant higher median levels of heme $(59.3 \mu \mathrm{M})$ than malaria positive women who did not take iron supplements $(36.5 \mu \mathrm{M}), p=0.04$ (figure 5).

\section{Iron supplementation in pregnancy is associated with increased plasma $\mathrm{HO-1}$ in women with malaria}

Iron supplementation was found to be associated with increased plasma HO-1 levels in women with malaria in this study. Women with malaria who took iron supplements had significant higher median levels of HO-1(6.2 ng/ ml) than women with malaria who did not take iron supplements $(2.9 \mathrm{ng} / \mathrm{ml}), p$ $=<0.001$ (figure 6).

\section{Increased free plasma heme is associated with preterm delivery}

Interestingly, the study found an association in increased free plasma heme and preterm delivery. Women who had preterm delivery had significant higher median levels of heme $(63.2 \mu \mathrm{M})$ than women who had full term delivery $(52.2 \mu \mathrm{M}), p=0.030$ (figure 7).

\section{Discussion}

Previous studies have demonstrated that placental malaria at delivery was associated with an increased risk of LBW and PTD [29]. This led us to hypothesize that parasite derived factors and host factors such as heme and heme oxygenase-1 play a role in the pathogenesis of malaria. In malaria-endemic areas, a significant proportion of individuals considered asymptomatic, carry parasites without presenting signs and symptoms of clinical malaria [30]. It is important to note that the women enrolled in this study were asymptomatic for malaria during labor. In this study, we demonstrated that pregnant women in general who took iron supplements had significantly higher levels of heme and HO-1 than pregnant women who did not take iron supplements. Among malaria positive pregnant women, those who took iron supplements had significantly higher heme and HO-1 levels than those who did not take iron supplements. We also showed that malaria positive pregnant women had increased plasma heme and HO-1 than malaria negative pregnant women. In addition we showed that, pregnant women who had preterm deliveries had increased plasma heme than pregnant women who did not have preterm deliveries. Pregnant women were supplemented with iron not according to disease or any clinical background or health issues, but due to socioeconomic reasons and availability of iron supplements. The observations made from this asymptomatic group can be predictors of more severe outcomes in a population with mild and severe malaria.

Recent studies have shown that the pathogenesis of severe malaria is not only due to parasitemia but also to parasite derived factors and host factors such as heme and Heme Oxgenase-1 (HO1) as a result of hemolysis. We reported that free heme and heme mediated signaling pathways are central in the pathogenesis of severe malaria [18]. We have previously shown that excess free heme, a product of hemolysis associated with erythrocyte damage

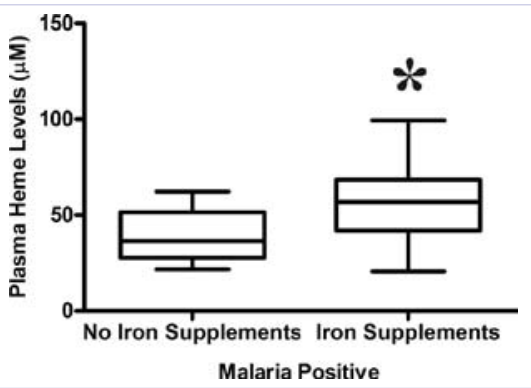

Figure 5: Free plasma heme levels among malaria positive pregnant women with or without iron supplementation. Mann Whitney test was used to compare for statistical differences in heme levels among malaria positive pregnant women who took iron supplements. Statistical significance was set at $P<0.05$.

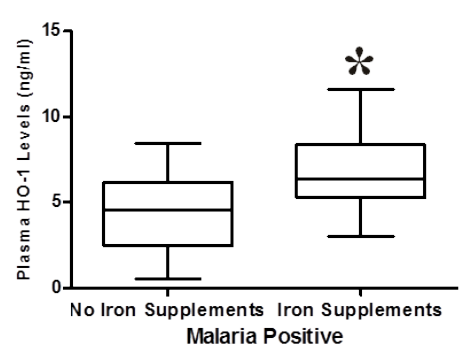

Figure 6: Plasma HO-1 levels among malaria positive pregnant women with or without iron supplementation. Mann Whitney test was used to compare for statistical differences in HO-1 levels among malaria positive pregnant women who took iron supplements. Statistical significance was set at $P<0.05$.

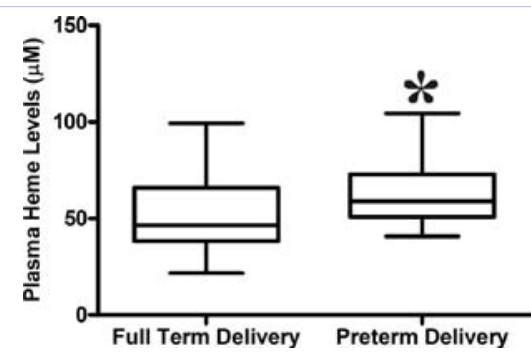

Figure 7: Free plasma heme levels among women with or without preterm delivery. Mann Whitney test was used to compare for statistical differences in heme levels among malaria positive pregnant women with preterm deliveries. Statistical significance was set at $P<0.05$.

due to malaria infection, compromises the blood brain barrier causing the barrier to become leaky and dysfunctional thereby exacerbating cerebral malaria complications [23]. Other papers have implicated HO-1 in the pathogenesis of severe preeclampsia [20] which demonstrates that the heme oxygenase system is an important regulator of placental development [24].

Heme is an extremely important molecule involved in various biological reactions, such as oxygen transport, respiration, drug detoxification and signal transduction [31]. However, circulating free heme is cytotoxic to the host and can trigger an intense oxidative burst and unspecific tissue damage [28]. This deleterious effect is countered by the up-regulation of the heme 
catabolizing enzyme Heme Oxygenase-1 (HO-1), encoded by the Hmox1 gene that catabolizes heme into iron ( $\mathrm{Fe})$, biliverdin and Carbon Monoxide (CO) [23,32]. Severe hemolysis occurring in diseases like sickle cell disease, ischemia reperfusion, and malaria results in high levels of free heme, causing undesirable toxicity in organ, tissue, and cellular injury [31,33]. Free heme is a prolific source of redox-active iron that is involved in the Fenton reaction to produce toxic free hydroxyl radicals [34]. ROS damage lipid membranes, proteins and nucleic acids, activate cell signaling pathways and oxidant sensitive, pro-inflammatory transcription factors, change protein expression, and disturb membrane channels [34,35]. According to Kumar, et al. [31], free heme catalyzes the oxidation, covalent cross-linking and aggregate formation of protein and its degradation to small peptides. It also catalyzes the formation of cytotoxic lipid peroxide via lipid peroxidation, which enhances membrane permeability, thereby stimulating cell lysis and death and damages DNA through oxidative stress [31,36,37]. Heme impairs lipid bilayers and organelles, such as mitochondria and nuclei, and destabilizes the cytoskeleton by injecting itself in the membrane [31,37]. Heme is a potent hemolytic agent and alters the conformation of cytoskeletal protein in red cells [38]. Free heme causes endothelial cell injury, leading to vascular inflammatory disorders and stimulates the expression of intracellular adhesion molecules [31,39]. Belcher, et al. [40] showed how Heme Oxygenase-1 (HO-1) alleviates vascular inflammation and vaso-occlusion in murine models of Sickle Cell Disease (SCD). They demonstrated that hemoglobin, heme and iron derived from hemolysis of sickle red blood cells in murine models of SCD, foster excessive ROS production resulting in vaso-occlusion and vascular inflammation via endothelial cell activation and expression of adhesion molecule on the vessel wall. This damaging effect is countered by the upregulation of HO-1 in the endothelium thereby alleviating and preventing vasoocclusion and the subsequent vascular inflammation frequently seen in SCD patients [40]. Other heme scavenging systems that are available in mammals to avert extracellular heme toxicity besides the Heme Oxygenase (HO) system include Haptoglobin (Hp) [41,42] and Hemopexin (Hx) [37] and albumin[31]. These heme scavenging systems detoxify free heme by forming a non-toxic heme complex or by its degradation or by scavenging free redoxactive iron (ferritin) released after heme catabolism [31]. Free hemoglobin released during hemolysis is captured by its carrier $\mathrm{Hp}$ and transported to macrophages of the reticuloendothelial system where it is bound by the scavenger receptor CD163. When the plasma Hp capacity is overwhelmed, hemoglobin is rapidly oxidized to methemoglobin, which releases free heme [43]. $\mathrm{Hx}$ is primarily expressed in the liver, brain and retina and it is a 57-kDa acute phase plasma glycoprotein able to bind equimolar amount of heme and move it into circulation [37,44]. Hx serves the role of a heme scavenger by maintaining lipophilic heme in a soluble state in aqueous environment and is essential in the reutilization of heme-bound iron and prevention of heme-induced oxidative damage and cell death [45]. Albumin complexes with heme can avert the toxic effects of extracellular heme in blood plasma [46]. Heme-albumin complex acts as a heme depot [47] and when Hx is exhausted, heme can bind wholly to albumin [48].
Iron supplementation during pregnancy increases the iron stores of the mother. There are two contradictions surrounding the health of pregnant women in malaria endemic areas with regards to iron supplementation [49]. This is because low levels of iron during pregnancy reduce parasite viability but high levels of iron promote parasite replication in red blood cells. The replication of plasmodium inside red blood cells leads to hemolysis and the subsequent release of cell-free hemoglobin $[28,50]$. In the presence of Reactive Oxygen Species (ROS) cellfree hemoglobin is readily oxidized into its heme prosthetic groups $[29,51]$. Circulating free heme is cytotoxic to the host and can trigger an intense oxidative burst and unspecific tissue damage [28].

Many factors can contribute to PTD, so we assessed the factors associated with PTD in this specific population. We observed that Parity $(p=0.036)$, weekly Income $(p<0.0001)$ and marital status ( $p=0.011$ ) were associated with PTD. We have shown in this study that pregnant women who took iron supplements had increased plasma heme levels than pregnant women who did not take iron supplements. We have also shown that, pregnant women who had preterm deliveries had increased plasma heme than pregnant women who did not have preterm deliveries. We also showed that malaria positive pregnant women had increased plasma heme/ HO-1 than non-malaria pregnant women.

Numerous studies have highlighted the benefits of iron supplementation, and some have shown us the adverse outcomes as well. For example, a study conducted on Tanzanian children, showed increased mortality among the children who received iron supplementation [15]. Risks and benefits of iron supplementation need to be further examined. Although iron supplementation presents a lot of benefits when the pregnant woman is iron deficient, there may be risks to mothers who are not iron deficient. The study was limited in that it was not originally designed as an iron supplementation trial. Some information about iron supplementation was not available like, iron supplementation dose and ferritin levels. We also do not have information on how many malaria episodes the women had throughout the course of their pregnancy. Therefore our analyses are limited.

In the course of this study, many interesting questions arose such as how does imbalance of the heme/ HO-1 system affect placental cells or fetal development? Is there any genetic variation in pregnant women to producing higher or lower levels of HO-1? If so will this affect pregnancy outcomes? Can these factors be targeted for future development of preventive chemotherapy against both parasites and hemolysis or heme production in pregnancy during malaria infection? We are currently examining the association between Heme and HO-1 levels and birth outcomes. We are also looking at the effect of heme on trophoblast cells (BeWo cells) and also determining Polymorphism(s) in HO-1 Gene and its association with pregnancy outcomes in pregnant women with malaria and without malaria. The results of this study are significant in the field of iron supplementation research in general and individuals who suffer hemolysis due to other causes including bacterial and hemorrhagic fevers. These 
observations in our view stimulate new research directions that may lead to development of novel adjuvant therapy to protect against malaria-associated morbidities and mortalities in pregnancy. A more robust and larger prospective study is needed to confirm these results.

\section{Acknowledgments}

The authors thank Mr. Ali and Mr. George at Korle-Bu Teaching Hospital for sample collection. The authors thank Dr. Pauline Jolly's lab at University of Alabama School of Public Health for making available archived samples. We also thank the staff at the labor wards of Komfo Anokye Teaching Hospital, Manhyia Polyclinic, University of Ghana Korle-Bu Teaching Hospital Department of Pathology and laboratory technicians for assisting with this work. Special thanks go to all the pregnant women who participated in this study.

\section{Ethics approval and consent to participate}

IRB approval was sought and approved by Morehouse School of Medicine and the Committee on Human Research, Publications and Ethics, School of Medical Sciences, Kwame Nkrumah University of Science and Technology Kumasi and The Korle Bu Teaching Hospital Accra for this study. Each participant of the study signed an informed consent form and parent/guardian signed a written informed consent form on behalf of the minors/ children enrolled in the study.

\section{Consent for publication}

All Authors give their consent for publication.

\section{Competing Interests}

The authors have declared that no competing interests exist.

\section{Availability of data and materials}

All data are fully available without restriction.

\section{Authors' contributions}

Conceived and designed the experiments: HS JKS. Performed the experiments: HS ML. Analyzed the data: HS NOW. Contributed reagents/materials/analysis tools: NY JKCT NOW ML CDC PJRGAJ JKS. Wrote the paper: HS JKS. Institutional facilities: AA RJCT NY. Subject recruitment: NYCT KB. Sample collection: HSNY PJ.

\section{Funding}

This work was supported by Grant R01 NS091616 from the National Institute of Neurological Disorders and Stroke (NINDS), T-32 Sleep/Cardiovascular Grant \#5T32HL103104-02, and Minority Biomedical Research Support Program (NIH/NIGMS) Grant \# 2R25GM058268. "The funders had no role in study design, data collection and analysis, decision to publish, or preparation of the manuscript."

\section{References}

1. World Health Organization. WHO Malaria Report 2015. Geneva Switzerland. 2015.

2. Fleming AF, Allan NC, Stenhouse NS. Haemolytic anaemia in pregnancy in Nigeria: recognition by simple laboratory procedures. West Afr Med J Niger Pract. 1969;18(3):82-8.
3. Fleming AF. Tropical obstetrics and gynaecology. 1. Anaemia in pregnancy in tropical Africa. Trans R Soc Trop Med Hyg. 1989;83(4):441-8.

4. Fleming AF. The aetiology of severe anaemia in pregnancy in Ndola, Zambia. Ann Trop Med Parasitol. 1989;83(1):37-49.

5. McGregor IA, Wilson ME, Billewicz WZ. Malaria infection of the placenta in The Gambia, West Africa; its incidence and relationship to stillbirth, birthweight and placental weight. Trans R Soc Trop Med Hyg. 1983;77(2):232-44.

6. Steketee RW, Wirima JJ, Hightower AW, Slutsker L, Heymann DL, Breman JG. The effect of malaria and malaria prevention in pregnancy on offspring birthweight, prematurity, and intrauterine growth retardation in rural Malawi. Am J Trop Med Hyg. 1996;55(1 Suppl):33-41.

7. Sullivan AD, Nyirenda T, Cullinan T, Taylor T, Harlow SD, James SA, et al. Malaria infection during pregnancy: intrauterine growth retardation and preterm delivery in Malawi. J Infect Dis. 1999;179(6):1580-3.

8. Sullivan AD, Nyirenda T, Cullinan T, Taylor T, Harlow SD, James SA, et al. Malaria infection during pregnancy: intrauterine growth retardation and preterm delivery in Malawi. J Infect Dis. 1999;179(6):1580-3.

9. American College of Obstetricians and Gynecologists. ACOG Practice Bulletin No. 95: anemia in pregnancy. Obstet Gynecol. 2008;112(1):201-7. doi: 10.1097/AOG.0b013e3181809c0d.

10. Bhutta ZA, Ahmed T, Black RE, Cousens S, Dewey K, Giugliani E, et al. What works? Interventions for maternal and child undernutrition and survival. Lancet. 2008;371(9610):417-40. doi: 10.1016/S01406736(07)61693-6.

11. Scholl TO. Iron status during pregnancy: setting the stage for mother and infant. Am J Clin Nutr. 2005;81(5):1218S-1222S.

12. Cao C, O'Brien KO. Pregnancy and iron homeostasis: an update. Nutr Rev. 2013;71(1):35-51. doi: 10.1111/j.1753-4887.2012.00550.x.

13. Sazawal S, Black RE, Ramsan M, Chwaya HM, Stoltzfus RJ, Dutta A, et al. Effects of routine prophylactic supplementation with iron and folic acid on admission to hospital and mortality in preschool children in a high malaria transmission setting: community-based, randomised, placebo-controlled trial. Lancet. 2006;367(9505):133-43.

14. Soofi S, Cousens S, Iqbal SP, Akhund T, Khan J, Ahmed I, et al. Effect of provision of daily zinc and iron with several micronutrients on growth and morbidity among young children in Pakistan: a clusterrandomised trial. Lancet. 2013;382(9886):29-40. doi: 10.1016/ S0140-6736(13)60437-7.

15. Clark MA, Goheen MM, Fulford A, Prentice AM, Elnagheeb MA, Patel J, et al. Host iron status and iron supplementation mediate susceptibility to erythrocytic stage Plasmodium falciparum. Nat Commun. 2014;5:4446. doi: $10.1038 /$ ncomms5446.

16. Scholl PF, Tripathi AK, Sullivan DJ. Bioavailable iron and heme metabolism in Plasmodium falciparum. Curr Top Microbiol Immunol. 2005;295:293-324.

17. Clark MA, Goheen MM, Cerami C. Influence of host iron status on Plasmodium falciparum infection. Front Pharmacol. 2014;5:84. doi: 10.3389/fphar.2014.00084.

18. Liu M, Amodu AS, Pitts S, Patrickson J, Hibbert JM, Battle M, et al. Heme mediated STAT3 activation in severe malaria. PLoS One. 2012;7(3):e34280. doi: 10.1371/journal.pone.0034280.

19. Wilson NO, Solomon W, Anderson L, Patrickson J, Pitts S, Bond V, et al. Pharmacologic inhibition of CXCL10 in combination with anti- 
malarial therapy eliminates mortality associated with murine model of cerebral malaria. PLoS One. 2013;8(4):e60898. doi: 10.1371/ journal.pone.0060898.

20. George EM, Granger JP. Heme oxygenase in pregnancy and preeclampsia. Curr Opin Nephrol Hypertens. 2013;22(2):156-62. doi: 10.1097/MNH.0b013e32835d19f7.

21. Ahmed A, Cudmore MJ. Can the biology of VEGF and haem oxygenases help solve pre-eclampsia? Biochem Soc Trans. 2009;37(Pt 6):123742. doi: 10.1042/BST0371237.

22.Zhai D, Guo Y, Smith G, Krewski D, Walker M, Wen SW. Maternal exposure to moderate ambient carbon monoxide is associated with decreased risk of preeclampsia. Am J Obstet Gynecol. 2012;207(1):57 e1-9. doi: 10.1016/j.ajog.2012.03.022.

23. Pamplona A, Ferreira A, Balla J, Jeney V, Balla G, Epiphanio S, et al Heme oxygenase-1 and carbon monoxide suppress the pathogenesis of experimental cerebral malaria. Nat Med. 2007;13(6):703-10.

24. Levytska K, Kingdom J, Baczyk D, Drewlo S. Heme oxygenase-1 in placental development and pathology. Placenta. 2013;34(4):291-8 doi: 10.1016/j.placenta.2013.01.004

25. Yatich NJ, Funkhouser E, Ehiri JE, Agbenyega T, Stiles JK, Rayner JC, et al. Malaria, intestinal helminths and other risk factors for stillbirth in Ghana. Infect Dis Obstet Gynecol. 2010;2010:350763. doi: $10.1155 / 2010 / 350763$.

26. Dhorda M, Piola P, Nyehangane D, Tumwebaze B, Nalusaji A, Nabasumba $C$, et al. Performance of a histidine-rich protein 2 rapid diagnostic test, Paracheck $\mathrm{Pf} \AA$, for detection of malaria infections in Ugandan pregnant women. Am J Trop Med Hyg. 2012;86(1):93-5. doi: 10.4269/ajtmh.2012.10-0631

27. Sethabutr O, Brown AE, Panyim S, Kain KC, Webster HK, Echeverria P. Detection of Plasmodium falciparum by polymerase chain reaction in a field study. J Infect Dis 1992;166(1):145-8.

28. Yatich NJ, Yi J, Agbenyega T, Turpin A, Rayner JC, Stiles JK, et al. Malaria and intestinal helminth co-infection among pregnant women in Ghana: prevalence and risk factors. Am J Trop Med Hyg. 2009;80(6):896-901.

29. Yatich NJ, Jolly PE, Funkhouser E, Agbenyega T, Rayner JC, Ehiri JE, et al. The effect of malaria and intestinal helminth coinfection on birth outcomes in Kumasi, Ghana. Am J Trop Med Hyg. 2010;82(1):28-34. doi: 10.4269/ajtmh.2010.09-0165.

30. Greenwood BM. Asymptomatic malaria infections--do they matter? Parasitol Today 1987;3(7):206-14

31. Kumar S, Bandyopadhyay U. Free heme toxicity and its detoxification systems in human. Toxicol Lett. 2005;157(3):175-88.

32. Otterbein L, Sylvester SL, Choi AM. Hemoglobin provides protection against lethal endotoxemia in rats: the role of heme oxygenase-1. Am J Respir Cell Mol Biol. 1995;13(5):595-601.

33. Gutteridge JM, Smith A. Antioxidant protection by haemopexin of haem-stimulated lipid peroxidation. Biochem J. 1988;256(3):861-5.

34. Vercellotti GM, Balla G, Balla J, Nath K, Eaton JW, Jacob HS. Heme and the vasculature: an oxidative hazard that induces antioxidant defenses in the endothelium. Artif Cells Blood Substit Immobil Biotechnol. 1994;22(2):207-13.

35. Jeney V, Balla J, Yachie A, Varga Z, Vercellotti GM, Eaton JW, et al. Pro-oxidant and cytotoxic effects of circulating heme. Blood 2002;100(3):879-87.
36. Miller YI, Shaklai N. Oxidative crosslinking of LDL protein induced by hemin: involvement of tyrosines. Biochem Mol Biol Int. 1994;34(6):1121-9.

37.Tolosano E, Fagoonee S, Morello N, Vinchi F, Fiorito V. Heme scavenging and the other facets of hemopexin. Antioxid Redox Signal. 2010;12(2):305-20. doi: 10.1089/ars.2009.2787.

38. Kirschner-Zilber I, Rabizadeh E, Shaklai N. The interaction of hemin and bilirubin with the human red cell membrane. Biochim Biophys Acta. 1982;690(1):20-30.

39. Regan RF, Kumar N, Gao F, Guo Y. Ferritin induction protects cortical astrocytes from heme-mediated oxidative injury. Neuroscience 2002;113(4):985-94.

40. Belcher JD, Mahaseth H, Welch TE, Otterbein LE, Hebbel RP, Vercellotti GM. Heme oxygenase-1 is a modulator of inflammation and vasoocclusion in transgenic sickle mice. J Clin Invest. 2006;116(3):808-16.

41. Schaer DJ, Buehler PW. Cell-free hemoglobin and its scavenger proteins: new disease models leading the way to targeted therapies. Cold Spring Harb Perspect Med. 2013;3(6). pii: a013433. doi: 10.1101/cshperspect.a013433.

42. Schaer CA, Deuel JW, Bittermann AG, Rubio IG, Schoedon G, Spahn $\mathrm{DR}$, et al. Mechanisms of haptoglobin protection against hemoglobin peroxidation triggered endothelial damage. Cell Death Differ. 2013;20(11):1569-79. doi: 10.1038/cdd.2013.113.

43. Ascenzi P, Bocedi A, Visca P, Altruda F, Tolosano E, Beringhelli T, et al. Hemoglobin and heme scavenging. IUBMB Life 2005;57(11):749-59.

44.Tolosano E, Cutufia MA, Hirsch E, Silengo L, Altruda F. Specific expression in brain and liver driven by the hemopexin promoter in transgenic mice. Biochem Biophys Res Commun. 1996;218(3):694703.

45. Eskew JD, Vanacore RM, Sung L, Morales PJ, Smith A. Cellular protection mechanisms against extracellular heme. Heme-hemopexin, but not free heme, activates the $\mathrm{N}$-terminal c-jun kinase. J Biol Chem. 1999;274(2):638-48.

46. Grinberg LN, O’Brien PJ, Hrkal Z. The effects of heme-binding proteins on the peroxidative and catalatic activities of hemin. Free Radic Biol Med. 1999;27(1-2):214-9.

47. Smith A, Morgan WT. Hemopexin-mediated transport of heme into isolated rat hepatocytes. J Biol Chem. 1981;256(21):10902-9.

48. Sears DA. Disposal of plasma heme in normal man and patients with intravascular hemolysis. J Clin Invest. 1970;49(1):5-14.

49. Scholl TO. Iron status during pregnancy: setting the stage for mother and infant. Am J Clin Nutr. 2005;81(5):1218S-1222S.

50. Seixas E, Gozzelino R, Chora A, Ferreira A, Silva G, Larsen R, et al. Heme oxygenase- 1 affords protection against noncerebral forms of severe malaria. Proc Natl Acad Sci U S A. 2009;106(37):15837-42. doi: 10.1073/pnas.0903419106.

51. Ferreira A, Balla J, Jeney V, Balla G, Soares MP. A central role for free heme in the pathogenesis of severe malaria: the missing link? J Mol Med (Berl). 2008;86(10):1097-111. doi: 10.1007/s00109-008-03685. 